\title{
Estimation of Ship's Course for Sailing on Route by Navigation Simulation in Coastal Water
}

\author{
Haibo XIA*, Shigeaki SHIOTANI**, \\ Eiichi KOBAYASHI** and Nobukazu WAKABAYASHI**
}

\begin{abstract}
Ship weather routing system for transoceanic vessels has been studied for many years to achieve an economic and safe navigation. However, little is known about that for coastal sailing vessels. The purpose of this research is to develop a weather routing system for small vessels. We call it numerical navigation system. This paper mainly discusses one of its important functions: the ability for a vessel to sailing on the planned route as precisely as possible.

First, the outline of the numerical navigation system is introduced, and then a navigation simulation based on MMG mathematical model is revealed. Finally, on-board experiments are conducted and compared with the navigation simulation. The results confirm that the estimation accuracy of ship's course for the weather routing system is satisfactory.

Keywords : weather routing, navigation simulation, small vessel, coastal sailing

キーワード: ウェザー・ルーデング、航海シミュレーション、小型船舶、治岸航行
\end{abstract}

\section{Introduction}

Since the concept of ship weather routing emerged in the 1950's, it has been rapidly developed along with the dramatic progresses of numerical forecasting and computer modeling techniques ${ }^{(1)}$. Ship weather routing system can provide an optimum route prior to sailing and update it if necessary when sailing based on weather forecasting and navigation simulation. This enables vessels to avoid adverse weather and sea condition or take advantage of favorable ones. As a result, navigation can be economic and safe.

However, most previous studies on weather routing focused on transoceanic vessels, and few have been undertaken on small vessels sailing in coastal water. Actually, even in a shorter voyage, the cumulative sailing time is sufficient to deserve significant economic consideration. Furthermore, because of the diminishing petroleum oil reserves and the development of powerful high-speed engines, it is likely that the cost of fuel will be very high in the near future.

From such a point of view, we devoted to developing a weather routing system, we call it numerical navigation system, for small vessels sailing in coastal water. For such purpose, we have measured and simulated the drifting angles and the sailing distances caused by tidal current in different relative tidal directions by on-board experiments and computer simulations. The accuracy of the simulation was evaluated by comparing their results ${ }^{(2)}$. Similarly, experiments and simulations of wind effect were conducted and the accuracy of the simulation was evaluated $^{(3)}$. As an important part of this system, the accuracy of estimating a ship's course is reported in this paper.

\footnotetext{
* Student member Graduate School of Science and Technology, Kobe University, ( $\mathbf{T} 658-0022$ 5-1-1 Fukae-minami, Higasinada-ku, KOBE) 021d983n@stu.kobe-u.ac.jp

** Member Faculty of Maritime Sciences, Kobe University
} 


\section{Numerical navigation system}

A numerical navigation system is illustrated in Figure 1. From the various factors of weather and sea conditions, we focus on the wind, current, and waves relative to a ship's weather routing system. Traditionally, this information has been regarded and used as static information, such as the annual or monthly mean values recorded in nautical charts, hydrographic publications, weather charts, and wave charts. For a transoceanic passage, such data meet the requirements of numerical forecasting on the whole. However, in the case of coastal navigation from several hours to 1 or 2 days, shorter time intervals and more accurate navigational information are required because the weather and sea conditions change in a complex manner due to the influence of the coastal topography.

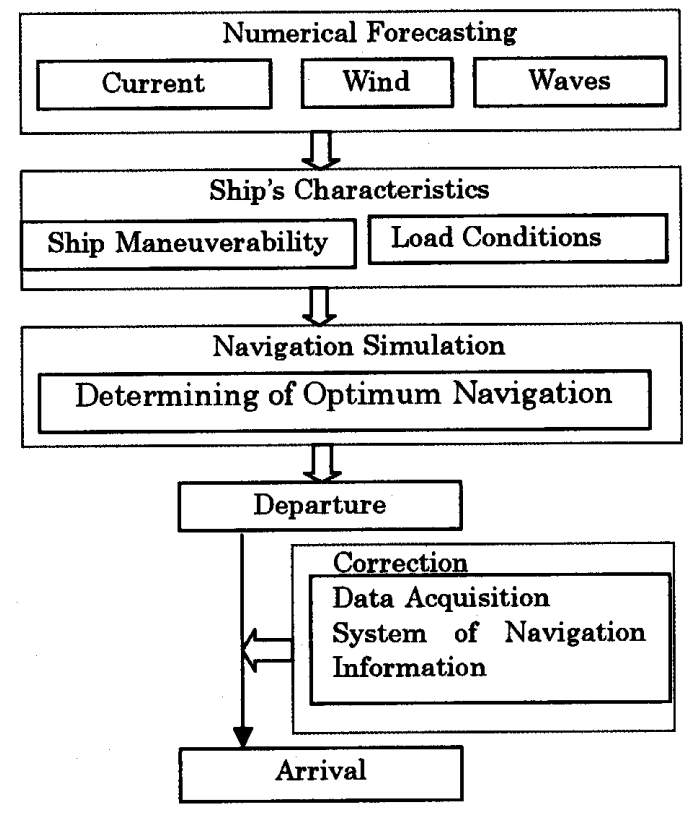

Fig. 1 Outline of numerical navigation system

In the first step of this system, the wind, current, wave and integrated fields of all these factors that may be encountered in navigation are numerically forecast.

The navigation simulation is conducted based on the forecast data of weather and sea conditions and ship's characteristics. As a result, an optimum route is selected from several ones between the point of departure and destination according to the minimum time or minimum fuel consumption. While sailing on the initial optimum route, real-time navigational information along the route is observed, collected, and analyzed automatically. When the diversion exceeds predetermined limits, the numerical forecasting and navigation simulation reported above will be conducted correspondingly to update the optimum route. In this manner, the route is optimized in real time until the voyage finished.

\section{Navigation simulation}

Even the effect of wave will also be considered into the numerical navigation system, only the effects of current and wind were taken into account. It will be studied in our future research.

Due to the effect of weather and sea conditions along the passage, diversions from the planned route inevitably occur. When these diversions are beyond the permitted value, the ship's heading is adjusted so that the ship returns to the planned route. In a numerical navigation system, this is achieved by navigation simulation based on real-time information of weather and sea conditions.

The mathematical model used in the navigation simulation is the MMG model, which is characterized by dividing all hydrodynamic forces and moments working on the vessel into the hull, rudder, and propeller and their interaction ${ }^{(4)(5)}$.

From the two coordinate systems shown in Figure 2, a space-fixed coordinate system and a body-fixed coordinate system, the latter, $G-x, y, z$, is adopted in the MMG model. This coordinate system moves together with the ship, where $G$ is the center of gravity of the ship, the $x$-axis is in the direction of ship heading, the $y$-axis is perpendicular to the $x$-axis on the right-hand side, and the $z$-axis is vertically downward through $G$.

Therefore, the equation of a ship's motion is written as

$$
\left.\begin{array}{c}
\left(m+m_{x}\right) \dot{u}-\left(m+m_{y}\right) v r=X \\
\left(m+m_{y}\right) \dot{v}+\left(m+m_{x}\right) u r=Y \\
\left(I_{z z}+J_{z z}\right) \dot{r}=N
\end{array}\right\}
$$

where $m$ is the mass, $m_{x}$ and $m_{y}$ are the added mass, and $u$ and $v$ are the components of the velocity in the direction of the $x$-axis and the $y$-axis, respectively. $r$ is the angular velocity. $I_{z z}$ and $J_{z z}$ are the moment of inertia and the added moment of inertia around $G$, respectively. $\mathrm{X}$ and $\mathrm{Y}$ are the hydrodynamic forces, and $\mathrm{N}$ is the moment around the $\mathrm{z}$-axis. 


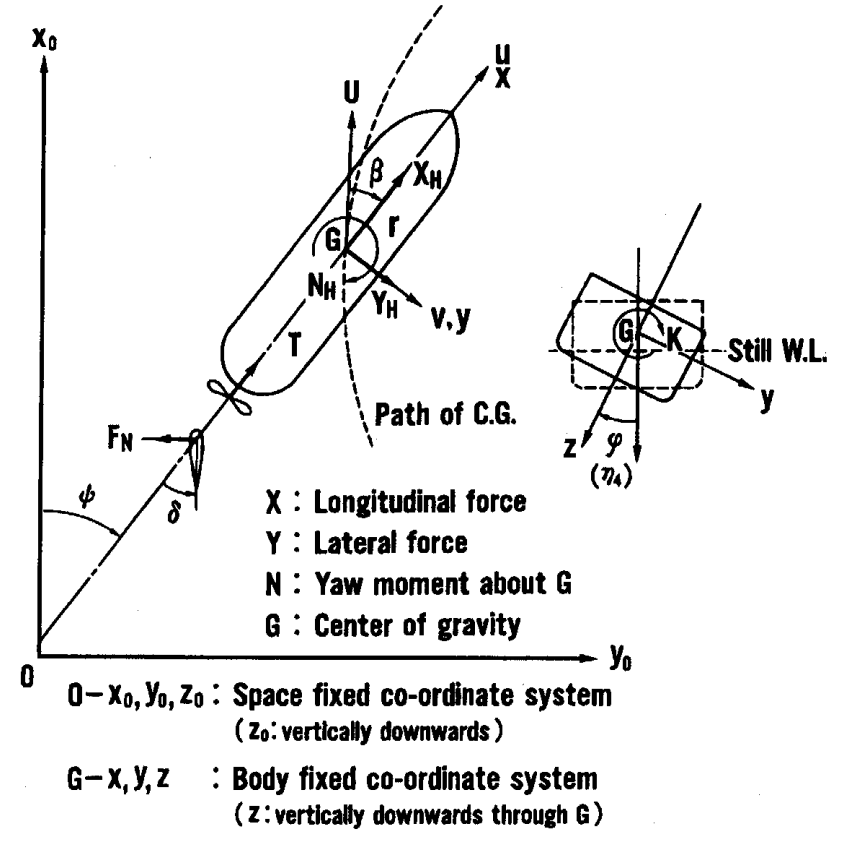

Fig. 2 Coordinate system of MMG

According to the MMG model, the hydrodynamic forces and the moment in the above equation can be written as below.

$$
\left.\begin{array}{c}
X=X_{H}+X_{P}+X_{R}+X_{T}+X_{A}+X_{W}+X_{E} \\
Y=Y_{H}+Y_{P}+Y_{R}+Y_{T}+Y_{A}+Y_{W}+Y_{E} \\
N=N_{H}+N_{P}+N_{R}+N_{T}+N_{A}+N_{W}+N_{E}
\end{array}\right\}
$$

where the subscripts $H, P, R, T, A, W$, and $E$ denote the hydrodynamic force or moment induced by the hull, propeller, rudder, thruster, air, wave, and external forces, respectively.

The hydrodynamic forces caused by the wind and current are defined in Equations (3) and (4).

$$
\left.\begin{array}{c}
X_{A}=1 / 2 \rho_{A} V_{A}^{2} A_{T} C_{X A}\left(\theta_{A}\right) \\
Y_{A}=1 / 2 \rho_{A} V_{A}^{2} A_{L} C_{Y A}\left(\theta_{A}\right) \\
N_{A}=1 / 2 \rho_{A} V_{A}^{2} L A_{L} C_{N A}\left(\theta_{A}\right)
\end{array}\right\}
$$

where $\rho_{A}$ is the density of air, $\theta_{A}$ is the relative wind direction, $V_{A}$ is the relative wind velocity, and $A_{T}$ and $A_{L}$ are the frontal projected area and the lateral projected area, respectively. $\mathrm{C}_{\mathrm{XA}}, \mathrm{C}_{\mathrm{YA}}$, and $\mathrm{C}_{\mathrm{NA}}$ are the coefficients.

$$
\begin{aligned}
X_{H}=1 / 2 \rho L d U^{2}\left(X_{v v}^{\prime} v^{\prime 2}+X_{r r}^{\prime} r^{\prime 2}\right. \\
\left.+X_{v v}^{\prime} v^{\prime} r^{\prime}+X_{v v v}^{\prime} v^{\prime 4}\right)-R \\
Y_{H}=1 / 2 \rho L d U^{2}\left(Y_{v}^{\prime} v^{\prime}+Y_{r}^{\prime} r^{\prime}+Y_{v v}^{\prime} v^{\prime 3}\right. \\
\left.+Y_{v v}^{\prime} v^{\prime 2} r^{\prime}+Y_{v r}^{\prime} v^{\prime} r^{\prime 2}+Y_{r r}^{\prime} r^{\prime 3}\right) \\
N_{H}=1 / 2 \rho L d U^{2}\left(N_{v}^{\prime} v^{\prime}+N_{r}^{\prime} r^{\prime}+N_{v v}^{\prime} v^{33}\right. \\
\left.+N_{v v r}^{\prime} v^{\prime 2} r^{\prime}+N_{v r}^{\prime} v^{\prime} r^{\prime 2}+N_{r r r}^{\prime} r^{\prime 3}\right)
\end{aligned}
$$

where $\rho$ is the density of sea water, $L$ is the length of the ship, $d$ is the draft, $U$ is the ship's speed, $v^{\prime}=v / U, \quad r^{\prime}=r L / U, \mathrm{R}$ is the resistance of the hull, $Y_{v}^{\prime}, Y_{r}^{\prime}, N_{v}^{\prime}$, and $N_{r}^{\prime}$ are linear derivatives, and $X_{v v}^{\prime}, X_{r r}^{\prime}, X_{v r}^{\prime}, X_{v v r}^{\prime}, Y_{v v}^{\prime}, Y_{v r}^{\prime}, Y_{v r}^{\prime}, Y_{m r}^{\prime}$, and $N_{v v}^{\prime} N_{v r}^{\prime} N_{v r}^{\prime} N_{m r}^{\prime}$ are non-linear derivatives.

\section{On-board experiments}

In order to obtain the actual information of the weather and sea conditions along the passage and evaluate the accuracy of the simulated ship's position, on-board experiments were conducted on "Fukaemaru," a training ship of Kobe University. Its principal particulars are shown in Table 1.

Table 1 Principal particulars of "Fukaemaru"

\begin{tabular}{|l|l|}
\hline Length (O.A.) & $49.95 \mathrm{~m}$ \\
\hline Length (P.P.) & $45.00 \mathrm{~m}$ \\
\hline Breadth (MLD.) & $10.00 \mathrm{~m}$ \\
\hline Depth (MLD.) & $6.10 \mathrm{~m}$ \\
\hline Draft (MLD.) & $3.20 \mathrm{~m}$ \\
\hline Gross Tonnage & $449 \mathrm{ton}$ \\
\hline Main Engine Output & $1,100 \mathrm{kw}$ \\
\hline Revolution & $720 \mathrm{rpm}$ \\
\hline Trial Speed & $14.28 \mathrm{kt}$ \\
\hline Sea Speed & $12.50 \mathrm{kt}$ \\
\hline Steering Engine & $3.7 \mathrm{kw}$ \\
\hline
\end{tabular}

The experiments were conducted in the coastal seas of south Shikoku, Japan. The ship ran on autopilot under the effect of weather and sea conditions for about 40 minutes in each case. Navigational information, such as the wind speed, wind direction, current speed, and tidal current direction, was observed at 0.5 -second intervals. The wind was measured using an on-board Combined Recording Wind Vane and Fan Anemograph. The current was measured at a depth of 2 meters using Doppler Anemometry. And the ship position was measured using DGPS.

The experimental ship, "Fukaemaru", uses an adaptive auto pilot which can achieve energy conservation. During experiment, the rudder limit was set to 5 degree, and the course alarm limit 10 degree.

Table 2 shows the information of ship, wind and current during the on-board experiments. The values 
Table 2 Information of ship, wind and current during the on-board experiments

\begin{tabular}{|l|l|l|l|l|l|l|}
\hline \multirow{2}{*}{ Case No. } & \multicolumn{2}{|l|}{ Ship } & \multicolumn{2}{l|}{ Wind } & Current \\
\cline { 2 - 7 } & $\begin{array}{l}\text { Course } \\
(\text { deg. })\end{array}$ & $\begin{array}{l}\text { Speed } \\
(\mathrm{kt})\end{array}$ & $\begin{array}{l}\text { Direction } \\
(\mathrm{deg} .)\end{array}$ & $\begin{array}{l}\text { Velocity } \\
(\mathrm{kt})\end{array}$ & $\begin{array}{l}\text { Direction } \\
(\mathrm{deg} .)\end{array}$ & $\begin{array}{l}\text { Velocity } \\
(\mathrm{kt})\end{array}$ \\
\hline 1 & 239.7 & 12.0 & 328.6 & 17.8 & 221.2 & 0.8 \\
\hline 2 & 225.7 & 12.0 & 226.6 & 11.6 & 221.2 & 0.8 \\
\hline 3 & 219.8 & 12.0 & 159.6 & 7.0 & 221.2 & 0.8 \\
\hline 4 & 199.9 & 12.0 & 328.6 & 17.8 & 221.2 & 0.8 \\
\hline 5 & 213.6 & 12.0 & 111.1 & 5.5 & 145.6 & 0.2 \\
\hline 6 & 56.2 & 12.0 & 300.1 & 16.6 & 271.9 & 0.4 \\
\hline
\end{tabular}

of wind and current in the table indicate their mean value over the experimental time.

\section{Comparison and analysis}

Although the information of weather and sea conditions used in a navigation simulation should be the results of numerical forecasting, actual data collected in on-board experiments were used at present stage.

Figures 3 4 show a sample of the time series of the wind and current during experimental navigation.

It can be seen from the figures that the wind and the tidal current changed clearly during the about 40-minute navigation. Especially the changes of tidal current are large because of its weakness. In a navigation simulation, the mean values of the wind and tidal current over a special time interval are used for the numerical calculation. A shorter time interval produces an accurate result; however, more computer calculation time is required.

By several navigation simulations using 5-minute 10-minute, 15-minute and 30-minute mean values, we found that 5-minute mean values of wind and tidal current was the most suitable time interval while considering the calculation time and estimation accuracy. For this reason 5-minute mean values of wind and tidal current were used in the following navigation simulation.
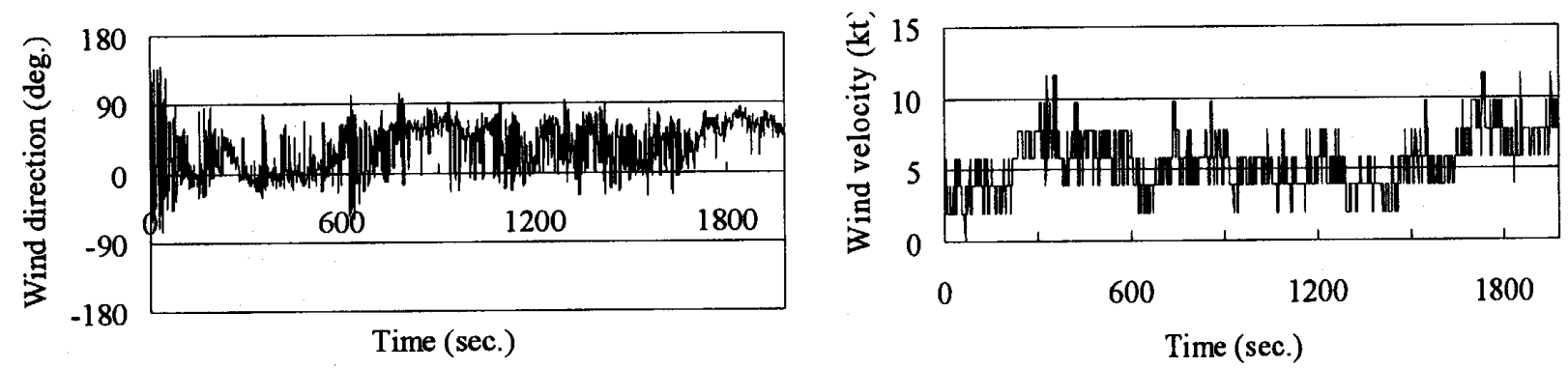

Fig. 3 Time series of the wind
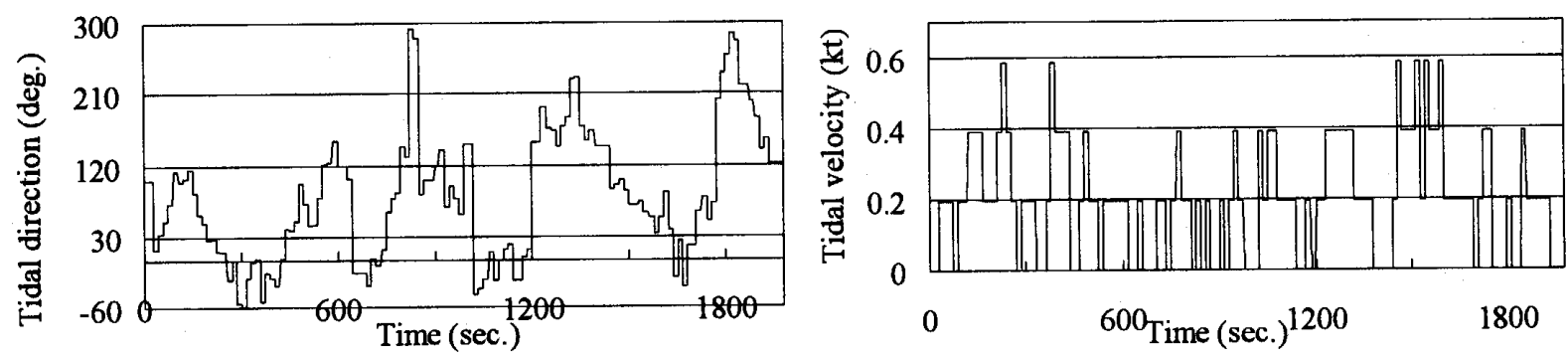

Fig. 4 Time series of the tidal current 
Figure 5 shows the ship's route in the experiment and the navigation simulation. The coordinate system in the figures is the geographic coordinate System, which uses degrees of latitude and longitude to identify a location on the earth's surface.

The wind and the tidal current are illustrated by solid and dotted lines with an arrow, respectively. It is noteworthy that the length of the arrows does not indicate the values of the wind and tidal current and is set for convenience. Furthermore, the values of the wind and tidal current shown in the figure are the mean values for the entire navigational period.

The setting course is shown as a thin line and was determined before departure to be followed during navigation. The thick line labeled as an experiment shows the ship's actual route during the
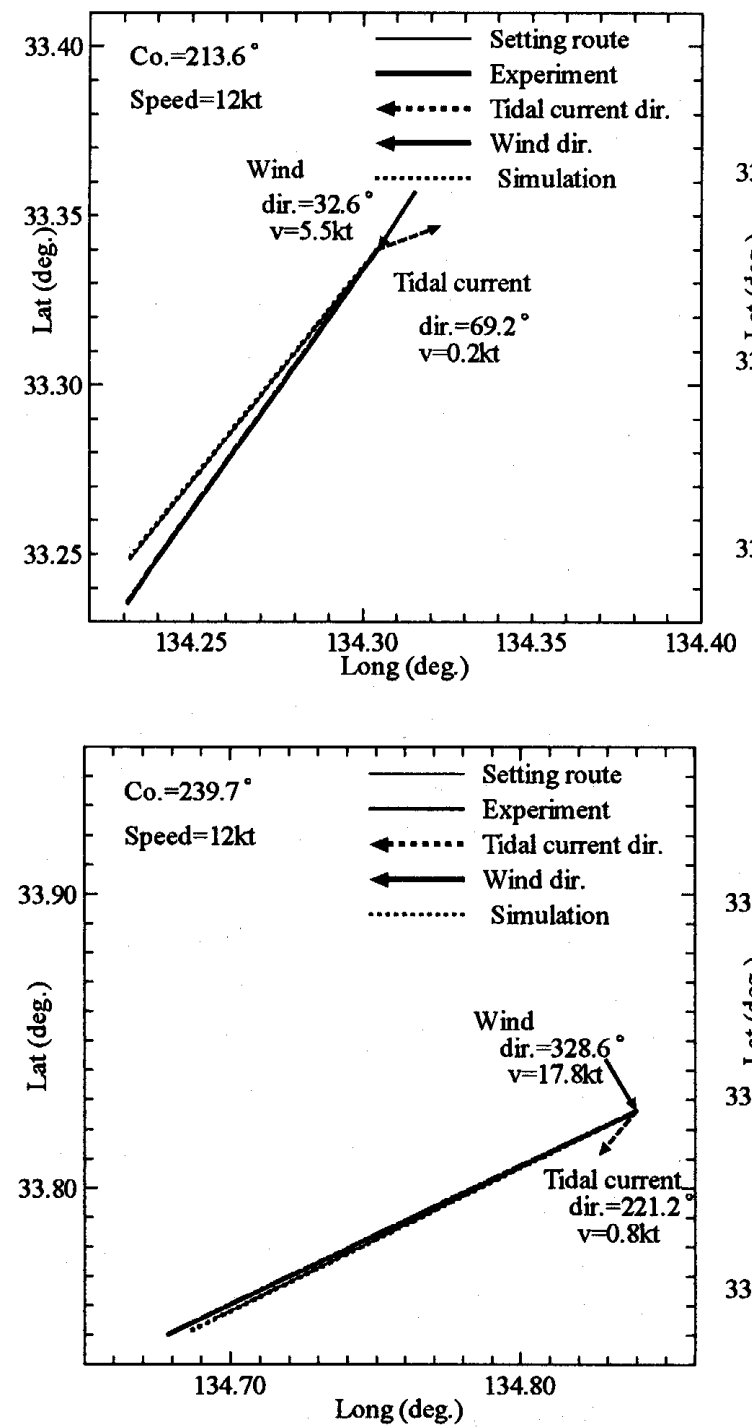

Fig. 5 Comparison of the ship's routes in the experiment and the navigation simulation
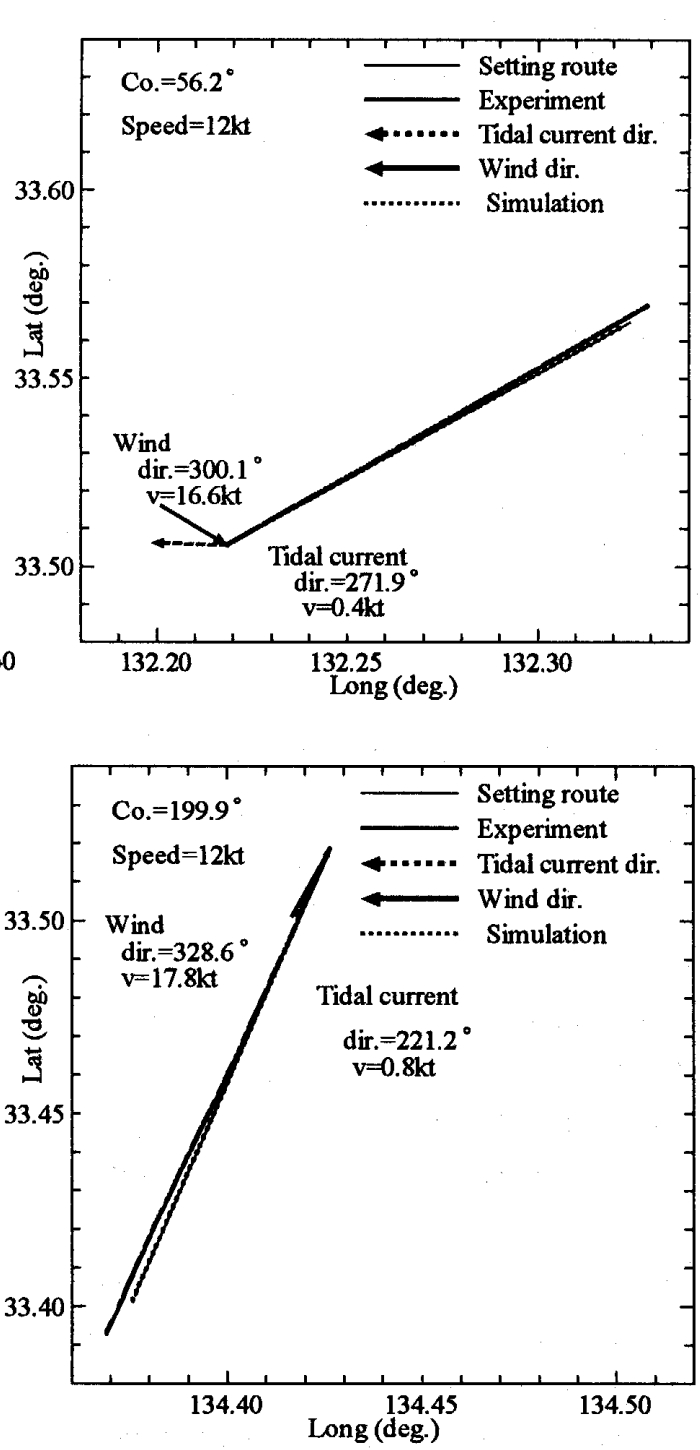

experimental navigation with the setting course on autopilot. The dotted line shows the results of the navigation simulation, which was conducted based on 5-minute mean values of the wind and current observed in the experimental navigation. In the navigation simulation, a new initial course, determined by the simulation on the basis of the effect of wind and current, is used in order to keep the vessel sailing on the setting course.

Figure 6 shows the Leeway and drift angle in the experiment and the navigation simulation.

Here, the leeway and drift angle are the angular difference between the ship's heading and the actual route due to the effects of the wind and current. The $\mathrm{x}$-axis is the case number and the $\mathrm{y}$-axis is the leeway and drift in degrees. The dotted line with a circle or the solid line with a triangle indicates the leeway and 


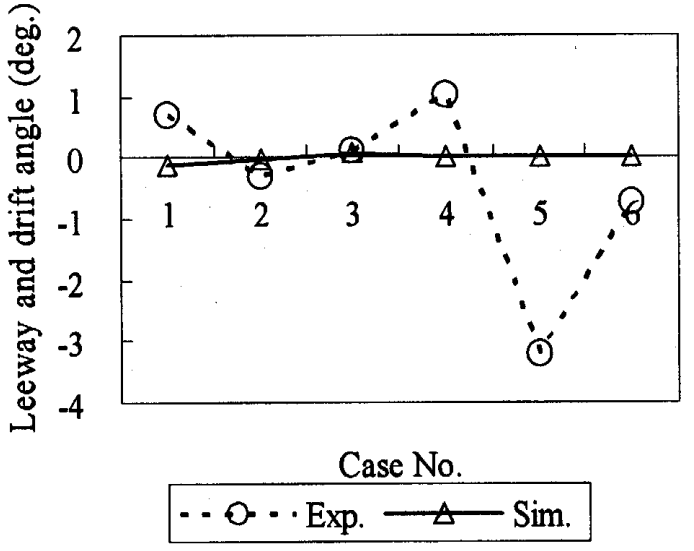

Fig. 6 Leeway and drift angle in the experiment and the navigation simulation

drift angle in the experiment navigation and the navigation simulation, respectively. Considering the navigation in narrow channel or high traffic density area, the permitted maximum value of drift angle deviated from the planning course was set to 0.5 degree.

The figure shows that the experimental navigation with the setting course in about 40 minutes will result in an obvious diversion form the setting route, whereas the leeway and drift angles in the navigation simulation are close to zero. In other words, the course determined by navigation simulation is accurate, showing that the estimation of the ship's course is effective.

\section{Conclusions}

The effectiveness of the numerical navigation system is determined by the validity of the forecasting of weather and sea conditions and the accuracy of the navigation simulation. At the present stage of construction the numerical navigation system for a small vessel sailing in coastal water, the estimation accuracy of ship's course for sailing on route is studied using on-board experiments and navigation simulations. From the analysis above, we conclude the following:

1) The construction of a numerical navigation system whereby vessels can accurately sail on the setting route is possible.

2) It is reasonable to use 5-minute mean values of wind and current data as initial conditions in navigation simulation for highly accurate simulations.
3) The leeway and drift angles of the navigation simulations are close to zero, and the estimation accuracy of a navigation simulation is satisfactory.

4) An advanced navigation simulation is anticipated if information of the wind and tidal current can be forecast in advance.

For the construction of a numerical navigation system, the future direction of this research will be to conduct a numerical forecast of the wind and current in coastal water and to consider the effect of the waves. Furthermore, the minimum time route and the minimum fuel consumption route are also needed to further study.

\section{Acknowledgements}

The authors express their gratitude to the captain and crew of the "Fukaemaru" for their kind support of the on-board experiment.

\section{References}

(1) Weather Routing Research Group : "Weather Routing -Optimum Routing Based on Weather Information," 1992

(2) Haibo XIA, Shigeaki SHIOTANI, et al.: "A Study of Weather Routing Considering Real Time Data of Weather and Ocean for Sailing Ship in Coastal Sea Area-Basic Simulation of Ship Positioning by Ship Maneuvering and Experiment by a Real Ship, " Journal of the Kansai Society of Naval Architects, Japan, No 234, pp.159-166, 2005

(3) Haibo XIA, Shigeaki SHIOTANI, et al.: "Field Experiment and Simulation of Drift Angle by Wind Effects Using an Actual Small Ship," The Journal of Japan Institute of Navigation, No.113, pp.171-177, 2005

(4) Kuniji KOSE et al.: "Concretization of the Mathematical Model of Ship Maneuverability," Proceedings of the 3rd Symposium on Ship Maneuverability, pp.28-81, 1981

(5) Takahiro OGAWA : "The Basics of a Mathematical Model of Ship Maneuverability," Proceedings of the 3rd Symposium on Ship Maneuverability, pp.9-26, 1981

\section{Question and Answers}

Mitsuru Hayashi (Kobe University):

What is the relationship between the experiment 
and the weather routing?

\section{Haibo Xia:}

Thank you for your question. In this paper, the experiments provide the data of weather and sea conditions for the weather routing system. Based on these data, an initial course is recommended by weather routing system. We conducted the navigation simulation using this recommended course and the results proved that the accuracy of estimation is satisfactory. In other words, if the information of weather and sea conditions can be known in advance, a recommended course can be provided by weather routing system to keep ship sailing on the setting route accurately.

The next step of our study is to conduct a numerical forecast of weather and sea conditions, and then the forecast data will be used instead of experimental data.

Akira Nagasawa (Japan Coast Guard Academy):

Due to a short sailing distance, the route changes maybe result in an obvious increase of sailing time and distance. What is the advantage of a weather routing system for such navigation?

\section{Haibo Xia:}

Thank you for your question. Weather routing system for coastal sailing can not only give route change recommendations while sailing, but also help to make navigation plan before sailing. Therefore, the more effective and safer navigation is possible.

The route changes made by weather routing system is a result of integrated consideration of safety, sailing time, and fuel consumption and so on. 